\title{
Analysis of Industrial Structure of Marine Economy in Jiangmen City Based on Multistage Deviation - Share Analysis Method
}

\author{
Jing ZHANGa, ${ }^{a}$ and Jian-Hua XIAO \\ Wuyi University School of Economics and Management, Jiangmen, Guangdong, 529020 \\ a2264546438@qq.com \\ ${ }^{*}$ Corresponding author
}

Keywords: Marine economy, Industrial structure, Deviation from share analysis.

\begin{abstract}
With the advent of the marine era, the development of marine economy has drawn more and more attention from the coastal provinces. Marine industrial structure is an important factor affecting the growth of marine economy. Based on the situation of marine industry development in Jiangmen, this paper analyzed and evaluated the characteristics of marine industrial structure in Jiangmen, and put forward some targeted optimization measures to provide the theoretical basis for the marine economic development in Jiangmen.
\end{abstract}

\section{The State of the Marine Economic Development in Jiangmen}

Jiangmen boasts rich marine resources such as islands, ports, tourism and fisheries, and has great potential for marine economic development. Since the "12th Five-year Plan", Jiangmen's marine economy has developed rapidly. The total marine product output of Jiangmen City in 2015 was RMB94.803 billion, an increase of $40.7 \%$ over 2012. The marine industry has enjoyed a good momentum of development. At present, the four major industries of marine shipbuilding industry, marine fishery industry, coastal tourism industry and marine transportation industry have become the major marine industrial systems in Jiangmen. However, while some progress has been made in marine industry in Jiangmen City, there have been increasingly prominent internal structural contradictions, which have led to insufficient development potential. Therefore, how to recognize the structural features of the marine industry in Jiangmen City, propose targeted optimization measures, it is particularly important to stand out in the spatial pattern of the national marine economic development.

\section{The Basic Principle and Mathematical Model of Deviation Share Analysis}

\section{The Basic Principle}

Daniel, the American economist, first proposed the basic principle of deviation-share analysis, which improved and summarized by Dunn, and extended it to the application in regional economic analysis.

The basic principle of the model is regard the change of regional economy as a dynamic process, and take the economic development of the region or the whole country as the frame of reference,then during a certain period of time decomposed the total economic of the region into three parts: the share deviations, the structural deviations and the departures from competitiveness, so as to illustrate the reasons for the regional economic development and recession, evaluation of the advantages and disadvantages of the regional economic structure and its own competitiveness, identify a relatively competitive industrial sector in the region [1].

\section{Mathematical Model}

Assuming that the the region total economic volume and structure have changed after time $(0, t)$, The total economic volume of the base period of region $\mathrm{i}$ is that $b$, the reporting period is $b_{n}$, At the same time, according to the classification of national economy by the State Council, the 
economy of area $\mathrm{i}$ is divided into $\mathrm{n}$ industrial departments. $b_{i j, 0}$ and $b_{i j, t}(\mathrm{j}=1,2, \ldots, \mathrm{n})$ represents the total economic volume of the industrial sector $\mathrm{j}$ of region $\mathrm{i}$ in the base period and reporting period. ${ }^{B_{0}}, B_{t}$ represent the total economic volume of the country during the base period and reporting period in the same period, ${ }^{B^{\prime \prime}}$ and ${ }^{B_{i n}}$ represent the total economic output of the $\mathrm{j}$-th industrial sector in the whole country in the same period as the base period and in the reporting period[2].

(1) The change rate of the $\mathrm{j}$-th industrial sector in region $\mathrm{i}$ at $(0, \mathrm{t})$ is:

$$
r_{i j}=\frac{b_{i j, t}-b_{i j, 0}}{b_{i j, 0}}(j=1,2, \ldots n)
$$

(2) The change rate of the national $\mathrm{j}$ industrial sector $(0, \mathrm{t})$ is:

$$
R_{j}=\frac{B_{j, t}-B_{j, 0}}{B_{j, 0}}(j=1,2, \ldots n)
$$

Based on the share of the various industrial sectors in the country, standardize the economic scale of the various industrial sector in the region $\mathrm{i}$ :

$$
b^{\prime}{ }_{i j}=\frac{b_{i, \mathrm{O}} * B_{j, 0}}{B_{\mathrm{O}}}(j=1,2, \ldots n)
$$

Therefore, the growth ${ }^{G_{i j}}$ of the jth industrial sector in region i during the $(0, \mathrm{t})$ time period can be decomposed into share deviation component $\left({ }^{N_{i j}}\right)$, structure deviations $\left(\boldsymbol{P}_{i j}\right)$ and competitiveness deviations $\left(D_{i j}\right)$

$$
\begin{gathered}
G_{\mathrm{ij}}=N_{\mathrm{ij}}+P_{\mathrm{ij}}+D_{\mathrm{ij}} \\
N_{\mathrm{ij}}=b_{i j}{ }^{\prime} R_{j} \\
P_{i j}=\left(b_{i j, o}-b_{i j}\right)^{\prime} R_{j} \\
D_{\mathrm{ij}}=\left(r_{i j}-R_{j}\right) * b_{i j, \mathrm{o}} \\
P D_{\mathrm{ij}}=P_{\mathrm{ij}}+D_{\mathrm{ij}}
\end{gathered}
$$

In the above, $N_{\mathrm{ij}}$ is the component of share deviation, which is the change of the regional standardized industrial sector according to the average national growth rate. ${ }^{N_{i j}}$ represents the development trend of the corresponding industrial sector in the standard region,the larger the value, the better growth industry in the region.$_{i j}$ is the component of structural deviation, refers to the regional department of the proportion of the corresponding departments differences caused by the regional i j sector growth relative to the national or regional standards deviations, which reflects the degree of advantage of the study area in the context of the national industrial development as a standard. $D_{i j}$ is the deviation component of competitiveness refers to the deviation caused by the difference between the growth rate of the $\mathrm{j}$ department in the region $\mathrm{i}$ and the growth rate of the corresponding department in the country or region, which reflects the degree of development of regional $\mathrm{j}$ industry and the relative competitive power of national or regional $\mathrm{j}$ industry.

The total economic growth in area i can be written as follows:

$$
G_{i}=N_{i}+P_{i}+D_{i}
$$

Meanwhile,in order to evaluate the overall industrial structure characteristics of the region, and introducing $K_{j, 0}=\frac{b_{i j, 0}}{B_{j, 0}}$ and $K_{j, t}=\frac{b_{i j, t}}{B_{j, t}}$ means that the proportion of sector $\mathrm{j}$ in the $\mathrm{i}$ region in the initial and final stages of the corresponding sectors throughout the country during the same period, then the relative growth rate of the region for the whole country $L$ is:

$$
Z=\frac{b_{j, t}}{B_{j, 0}}=\frac{B_{t}}{B_{0}}
$$


The structural effect index $\mathrm{W}$ and the competitive effect index $\mathrm{u}$ can be obtained after decomposition:

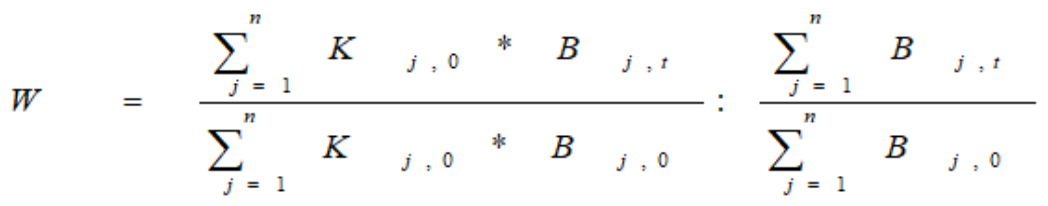

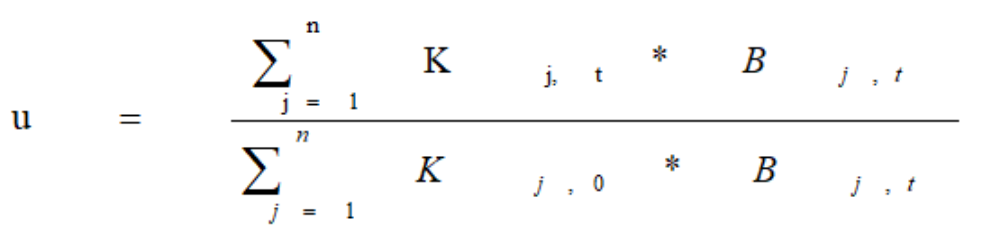

From the above expressions, if $G_{i j}$ larger, $L$ greater than 1, it shows that the regional growth is faster than the whole country or the large region; If ${ }_{P_{i}}$ is larger and $W$ is greater than 1, it shows that the fast-growing of the industrial sector has a large proportion, the overall economic structure of the region is better, and the structure has a great contribution to economic growth. If $D_{i j}$ is larger and $U$ is greater than 1, it shows that the total growth momentum of each industrial sector in the region is large and has strong competitiveness.

\section{Quantitative Analysis Based on Deviation from Share Model}

\section{Data Processing}

This article selects the output value of the major marine industries in Jiangmen City from 2012 to 2015 as well as the output data of marine fisheries, marine shipping industry, coastal tourism and other marine industries, with 2012 as the initial period and 2015 as the final period, taking the standard area of marine industry in Guangdong Province and the national marine industry as a reference, deviation-share analysis and comparative analysis were carried out. Through the comparison of the evaluation of marine industrial structure in Jiangmen from different perspectives, this paper analyzes the competitiveness and structural advantages of marine industry in Jiangmen City in Guangdong Province and the whole country.

All data sources of this paper are: Jiangmen City Ocean Statistical Report 2012-2015, Guangdong Marine Economic Statistics Bulletin 2012-2015 and National Oceanographic Statistical Yearbook 2012-2015.

Gross domestic product is the ultimate reflection of all economic activities in the sea and to some extent reflects the overall situation of marine economic development in the coastal areas. According to the relevant data, the total marine industrial output value of Jiangmen City in 2012-2015 has been showing a steady increase. From 67.379 billion yuan in 2012 to 94.803 billion yuan in 2015, an increase of $40.7 \%$. This not only shows that Jiangmen has been paying more attention to the development of marine economy in recent years, but also illustrates the importance of marine economy in promoting economic development in the region Pulling more and more power, land and sea economic development will be the future trend of economic development in our city and an important starting point.

By substituting the statistical data into the SSM model, we can get not only the deviation analysis table (Table 1 and Table 2) of Jiangmen City marine fishery, ocean shipping industry and coastal tourism in different references, but also get the growth rate, structural effect coefficient and competitive effect coefficient of Jiangmen's marine industry relative to Guangdong Province and the whole country (Table 3 ). 
Table 1 Jiangmen City, marine industry deviation from the share of the analysis (Guangdong Province as an example)[100 million yuan]

\begin{tabular}{|l|c|c|c|c|}
\hline Analysis of indicators & $\begin{array}{l}\text { Marine } \\
\text { fisherie } \\
\mathrm{s}\end{array}$ & $\begin{array}{l}\text { Marine shipbuilding } \\
\text { industry }\end{array}$ & $\begin{array}{l}\text { Coastal } \\
\text { tourism }\end{array}$ & $\begin{array}{l}\text { Other major } \\
\text { marine } \\
\text { industries }\end{array}$ \\
\hline Total growth $\left(G_{i j}\right)$ & 9.66 & -2.67 & 39.43 & 83.73 \\
\hline Share component $\left(N_{i j}\right)$ & 2.44 & 1.07 & 69.77 & 2.54 \\
\hline $\begin{array}{l}\text { Structure deviates from the } \\
\text { component }\left(P_{i j}\right)\end{array}$ & -0.32 & 1.3 & 23.21 & -1.01 \\
\hline $\begin{array}{l}\text { Regional competitiveness } \\
\text { deviates from the weight }\left(D_{i j}\right)\end{array}$ & 7.56 & 0.98 & -53.29 & 82.20 \\
\hline $\begin{array}{l}\text { Regional departmental } \\
\text { advantages }\left(P D_{i j}\right)\end{array}$ & 7.24 & -3.68 & -30.08 & 81.19 \\
\hline
\end{tabular}

Table 2 Jiangmen City, the marine industry deviation from the share of the analysis (Take the whole country as an example)[100 million yuan]

\begin{tabular}{|l|c|c|c|c|}
\hline Analysis of indicators & $\begin{array}{l}\text { Marine } \\
\text { fisheries }\end{array}$ & $\begin{array}{l}\text { Marine shipbuilding } \\
\text { industry }\end{array}$ & $\begin{array}{l}\text { Coastal } \\
\text { tourism }\end{array}$ & $\begin{array}{l}\text { Other major } \\
\text { marine } \\
\text { industries }\end{array}$ \\
\hline Total growth $\left(G_{i j}\right)$ & 9.66 & -2.67 & 39.43 & 84.29 \\
\hline Share component $\left(N_{i j}\right)$ & 9.33 & 1.43 & 52.52 & 19.71 \\
\hline $\begin{array}{l}\text { Structure deviates from the } \\
\text { component }\left(P_{i j}\right)\end{array}$ & -6.46 & 0.47 & 10.98 & -6.65 \\
\hline $\begin{array}{l}\text { Regional competitiveness } \\
\text { deviates from the weight }\left(D_{i j}\right)\end{array}$ & 6.8 & 0.51 & -23.81 & 70.68 \\
\hline $\begin{array}{l}\text { Regional departmental } \\
\text { advantages }\left(P D_{i j}\right)\end{array}$ & 0.34 & -4.04 & -12.83 & 64.03 \\
\hline
\end{tabular}

Table 3 Jiangmen City, under different ocean industrial structure overall effect

\begin{tabular}{|l|c|c|}
\hline Analysis of indicators & $\begin{array}{l}\text { With } \\
\text { Guangdong Province }\end{array}$ & Reference to the country \\
\hline Share component (N) & 75.82 & 40.88 \\
\hline Structure deviates from the component (P) & 23.18 & 54.18 \\
\hline Competitive deviation from the weight (D) & 37.45 & 47.5 \\
\hline Total deviation component( PD) & 54.67 & 1.09 \\
\hline The relative growth rate of the country (L) & 1.071 & 1.003 \\
\hline Structural effect index (W) & 0.998 & 1.086 \\
\hline Competitiveness index (U) & 1.073 & Take \\
\hline
\end{tabular}

Based on the above data, you can draw deviations - share analysis chart. Take advantage of regional industry $P D_{i j}$ (the sum of $\boldsymbol{P}_{i j}$ and $\boldsymbol{D}_{i j}$, reflecting the overall growth advantage of j

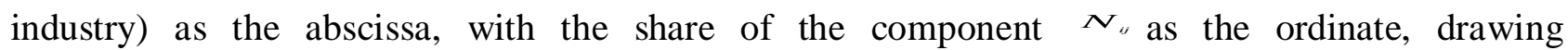
departmental advantages analysis, taking the competition deviation component $D_{i j}$ as the abscissa and the structure deviation component $\boldsymbol{P}_{i j}$ as the ordinate, the department deviation component diagram is drawn, from this, we can judge the strengths and weaknesses of the overall structure and competitiveness of the region, so as to determine the competitive industries. As shown in Figure 1 $(a, b)$ and Figure $2(a, b)$ : 


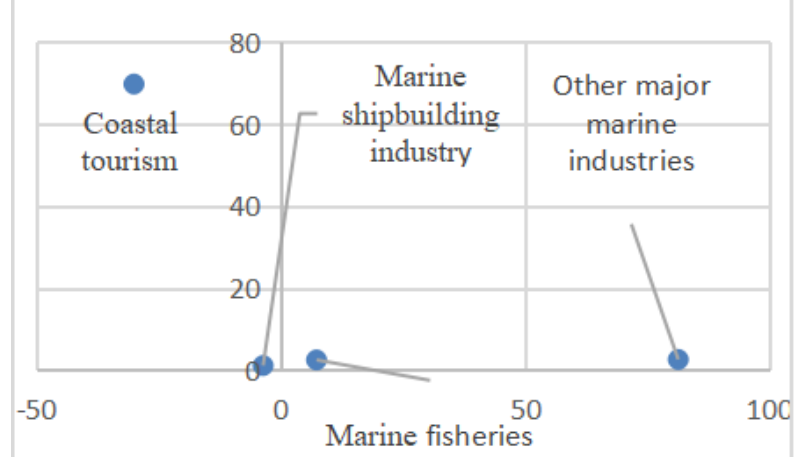

(a)Analysis of departmental advantages

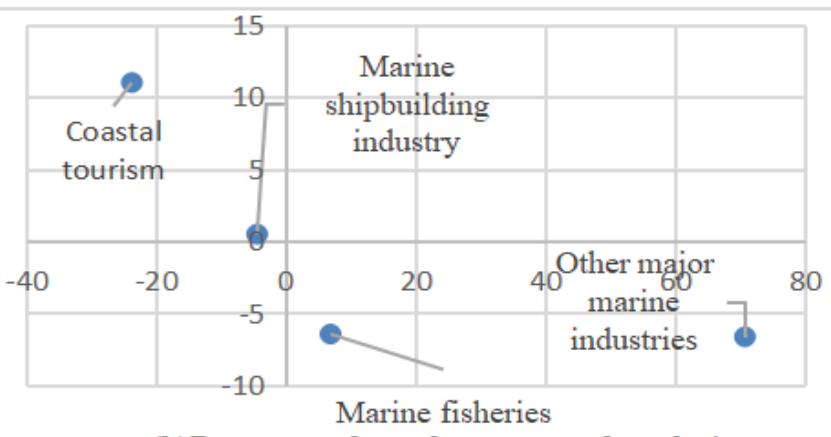

(b)Departure from departmental analysis

Fig. 1 Guangdong Province as a reference deviation from the share analysis

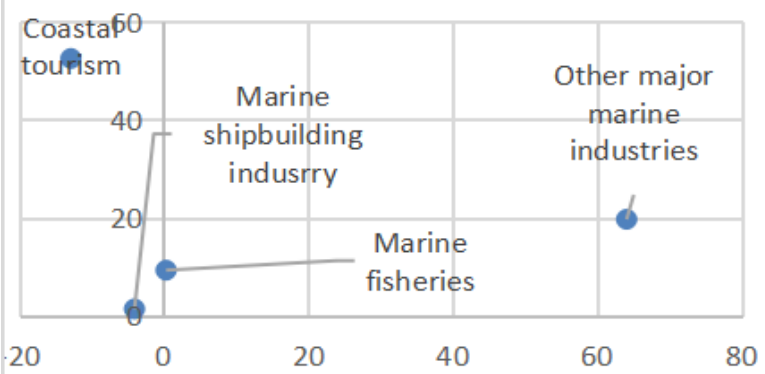

(a) Analysis of departmental advantages

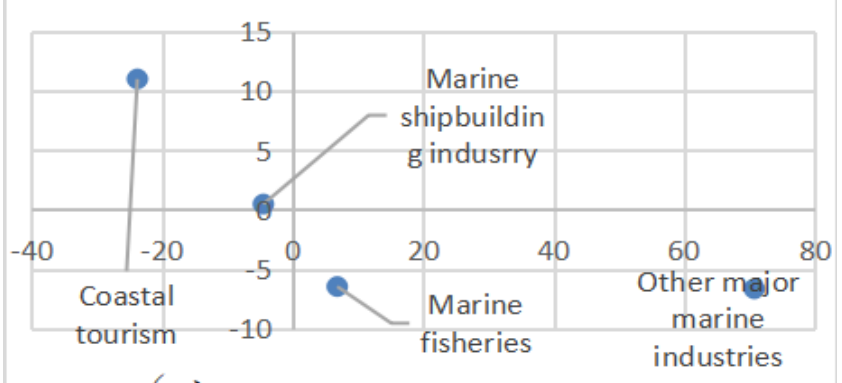

(b) Departure from departmental analysis

Fig. 2 Deviates from the share of the country as a reference analysis

\section{Data Analysis}

Regional Impact Status. As can be seen from Table 1 and Table 2, taking Guangdong province as a reference, the share of the marine industry in Jiangmen City is from the highest to the lowest in the coastal tourism, other major marine industries, marine fisheries, and marine shipping industries respectively, Reference when the shares of the same level of change.

The share of marine fishery in Guangdong Province is less than that of the national reference, and the total growth rate of marine fisheries in Guangdong Province (12.54\%) is lower than the national growth rate of marine fisheries (19.17\%) between 2012 and 2015, This shows that the relative speed of development of marine fisheries in Guangdong Province relative to the whole country is relatively slow.

The share of other major marine industries under Guangdong's reference is less than the share of the country's reference, and the growth rate of other major marine industries $(2.21 \%)$ is far below the growth rate of other major marine industries during 2012-2015 (17.45\%), indicating that the relative speed of development of other major marine industries in Guangdong Province relative to the whole country is relatively slow.

The share of marine vessels under the reference of Guangdong Province is less than the share of the country as a reference, but, the growth rate of marine shipping industry in Guangdong Province $(10.11 \%)$ is higher than that of the national marine shipping industry $(7.63 \%)$, indicating that the shipping industry in Guangdong Province has been developing at a relatively fast pace.

Coastal tourism in Guangdong Province, under the reference share component is greater than the national reference for the share of components, in 2012-2015, the growth rate of coastal tourism in Guangdong Province $(81.78 \%$ ) is higher than the growth rate of the coastal tourism industry (55.97\%), indicating that coastal tourism in Guangdong Province is developing rapidly relative to the whole country.

Overall Effect Analysis. According to Table 3 described Jiangmen marine industry deviate from the share of the overall effect, the total increment of marine economy in Jiangmen City from 2012 to 2015 was 27.424 billion yuan, which is larger than the share deviated from the total amount in Guangdong and the national total, compared with Guangdong Province and the national growth rate 
is greater than 1, this shows that the overall growth rate of marine economy in Jiangmen City was higher than that of the whole country and Guangdong Province.The structural deviation component in Guangdong is positive, and the structural effect index is close to 1, indicating that the marine economy of Jiangmen City is relatively better than that of Guangdong Province, but the advantage is not obvious, the structure needs further adjustment; in the whole country, the deviations of the structure are positive, and the structural effect index is greater than 1, indicating that the marine economy in Jiangmen has some advantages in the industrial structure at the national level; the deviations of competitiveness are both positive under different references, and the index of competitiveness effect is greater than 1, which shows that the growth of various industries in the marine economy in Jiangmen City has gained momentum and is highly competitive both in Guangdong Province and the whole country.

Structural Deviation and Regional Competitiveness from the Situation. When Guangdong Province and the whole country were taken as reference, the deviations of marine fishery structure in Jiangmen City were both negative, indicating that neither Guangdong Province nor the whole nation had structural advantages and the negative impact on Guangdong's marine industry was slightly less than that of the national level. Lies in the development of fisheries in Guangdong Province both in proportion and speed below the national level. marine fishery in Guangdong Province, the regional competitiveness of departure component of 756 million yuan, higher than the national competitiveness of the region deviate from the component 680 million yuan, this shows that marine fishery in Jiangmen City is relatively competitive in terms of Guangdong Province. To a certain extent, it has benefited from the relatively high capital and technical investment in mariculture, making marine fishery a relatively competitive one despite occupying a smaller share.

When Guangdong was taken as a reference, Jiangmen's industrial structure deviated from the marine structure reached 130 million, higher than the national reference of 47 million, indicating that Jiangmen Marine Shipbuilding Industry accounted for a large proportion of the total shipbuilding industry in Guangdong. The industrial structure of the total economy Great contribution to growth. Taking Guangdong and the whole country as a reference, Jiangmen Marine Marine Industrial Zone deviate from its competitive components are positive, indicating that shipbuilding industry in Jiangmen City, Guangdong Province and the national competitiveness occupy an advantage, rapid development.

When Guangdong was taken as a reference, the deviation of tourism structure in coastal area of Jiangmen reached 2.231 billion, higher than that of 1.098 billion with reference to the whole country, indicating that tourism in Jiangmen accounts for a large proportion of Guangdong's total tourist industry in the coastal area, Total contribution to growth. When the Guangdong area and the whole country are taken as a reference, the deviation of competitiveness of coastal tourism in Jiangmen City is negative, which shows that it is not dominant in the coastal tourism of Jiangmen City and the national competitiveness.

Combining sectoral advantage data ( $P D ")$ and deviation-share analysis chart can be found, no matter at what level, all marine industries in Jiangmen City have a great space for development. Among them, the marine fishery and other major marine industries have industrial advantages, while the maritime industry as well as coastal tourism industry advantage is not obvious, but has a lot of room for development. Jiangmen marine shipping industry, marine fisheries and other major marine industries in Guangdong Province advantage is greater than in the country's advantages; Jiangmen marine shipping industry belongs to the better-performing but declining industries in Guangdong Province, but it is a highly competitive industry at the national level; marine fishery is a relatively fast-growing industry in Guangdong and the whole country. tourism in Jiangmen coastal area belongs to a slow-growing industry in Guangdong and develops relatively slowly in the whole country. 


\section{Optimization of Industrial Structure in Jiangmen}

\section{Promote the Transformation of Traditional Fisheries to Modern Fisheries}

In accelerating the development of modern fisheries in Jiangmen train of thought, we must attach importance to the use of advanced concepts and tools. First, we must ensure the quality and safety of aquatic products, emphasizing both quantity and quality. Actively upgrade facilities and equipment such as processing and distribution of aquatic products, and establish a more standardized and scaled industrial system and quality and safety regulatory system to effectively guarantee the consumption safety of aquatic products; Second, on scientific and technological innovation and popularization and application, intensified research and development of deep processing of fishery products to further improve the quality and efficiency of fishery industry development; Third, we must further expand the fisheries industry chain, improve product added value. Such as expanding the role of fisheries in recreational tourism, landscaping and cultural inheritance, so as to further raise the incomes of local fishermen [3].

\section{Expand the Advantages of Industry, Develop Modern Ocean Shipping Industry}

First, we must vigorously develop the ship ancillary products. Rely on and with the advantage of Jiangmen City, a solid manufacturing base, and actively to ship parts supporting the direction of development; Second, we must pay attention to personnel training and planning. Jiangmen should attach importance to the training of top-level talents, actively cooperate with scientific research institutes, and encourage enterprises to cooperate with institutions of higher learning and research institutes to cultivate practical talents for research; Third, we must strengthen independent innovation and industrial upgrading. The enterprise as a carrier, the establishment of a combination of production and research cooperation in the operation mechanism of innovation and create a more complete innovation chain.

\section{Vigorously Develop Coastal Tourism Resources, Develop Coastal Tourism}

Jiangmen itself is rich in coastal tourism resources and has great potential for development. Jiangmen City should seize this opportunity of good development and speed up the development and utilization of coastal tourism resources. First, we must formulate a scientific and rational development plan. With Jiangmen own characteristics, formulate a scientific and distinctive long-term development plan, and strictly enforced; Second, we must strengthen infrastructure construction and ecological protection. For example, to make transportation more convenient and humane, in addition, we should pay attention to the protection of local ecology and minimize the damage to the natural landscape during the development process; Third, we must increase their marketing. The use of television stations, the Internet and other means to increase tourism and tourism in Jiangmen propaganda, timely according to the needs of tourists to adjust and strengthen the tourism facilities and services.

\section{Optimize the Industrial Layout, Support the Development of New Industries}

In order to realize the leapfrog development of marine economy in Jiangmen, the government must pay attention to the development of marine emerging industries [5].First of all, it is necessary to actively formulate development plans and optimize the industrial layout. In addition, we should strengthen the awareness of science and technology support and innovation, vigorously cultivate new marine industries with high science and technology content and low resource consumption, and further promote the marine economic development in Jiangmen.

\section{Acknowledgement}

This paper has been funded by Guangdong University for Innovation and Innovation Project "Research on Development and Research of Marine Industry in Dagu bay" (2016WTSCX114). 


\section{References}

[1] Feng Youjian, Zhu Wei. Analysis of Zhejiang Province's Ocean Industrial Structure in Different Sights - Based on Deviation-Share Analysis [J] .Marine Development and Management, 2016,33 (07): 15-20.

[2] Zhang Lian. Research on the Evaluation of Marine Industrial Structure and Competitiveness of China's Marine Economic Zone [D] .Liaoning Normal University, 2014.

[3] Zhao Li, Liu Fangna. Jiangmen marine economic development SWOT analysis and strategic options [J] .New economy, 2014 (07): 59-62.

[4] Li Ting. Jiangmen City, the competitiveness of coastal tourism [D]. Wuyi University, 2014.

[5] Ding Li. Research on the Development Mechanism of Marine Strategic Emerging Industries - A Case Study of Jiangmen City [J]. Brand, 2015 (08): 109-110 + 113. 